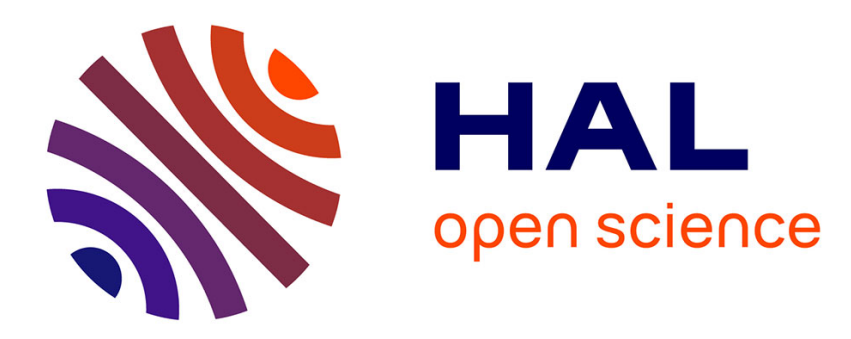

\title{
Methods for Ripple Index evaluation in DC Low Voltage Distribution Networks
}

\author{
Andrea Mariscotti
}

\section{To cite this version:}

Andrea Mariscotti. Methods for Ripple Index evaluation in DC Low Voltage Distribution Networks. 2007 IEEE Instrumentation \& Measurement Technology Conference IMTC 2007, May 2007, Warsaw, Poland. 10.1109/imtc.2007.379205 . hal-03257387

\section{HAL Id: hal-03257387 https://hal.science/hal-03257387}

Submitted on 10 Jun 2021

HAL is a multi-disciplinary open access archive for the deposit and dissemination of scientific research documents, whether they are published or not. The documents may come from teaching and research institutions in France or abroad, or from public or private research centers.
L'archive ouverte pluridisciplinaire HAL, est destinée au dépôt et à la diffusion de documents scientifiques de niveau recherche, publiés ou non, émanant des établissements d'enseignement et de recherche français ou étrangers, des laboratoires publics ou privés. 


\title{
Methods for Ripple Index evaluation in DC Low Voltage Distribution Networks
}

\author{
Andrea Mariscotti \\ Department of Electrical Engineering, University of Genoa \\ Via All'opera Pia 11A, 16145 Genova (GE), Italy \\ Phone: +39-010-353-2169, Fax: +39-010-353-2700, Email: codda@die.unige.it, mariscotti@die.unige.it
}

\begin{abstract}
Power Quality indices for ripple evaluation in DC Low Voltage networks are presented and discussed. Ripple is interpreted in a more general way than a simple periodic fluctuation of network voltage due to rectifying harmonics: the indices are conceived to cope with $P Q$ definition of several standards in terms of frequency range and related phenomena. The proposed $P Q$ indices are implemented for real-time execution; performances are evaluated in Matlab.
\end{abstract}

Keywords - Power Quality, Time domain analysis, Spectral analysis, Digital filters.

\section{INTRODUCTION}

In the recent years the number and the rated power of distributed energy generation facilities have grown. Several are the energy sources: renewable (wind mills, fuel cells, solar thermal, photovoltaic) and not renewable (diesel and micro-turbines). These sources exhibit different rated power range, output voltage range, transient capability, stability, but they have one common factor: they all (except the large part of diesel generators) are available in dc and are then connected to standard ac networks through dc/ac static converters (Voltage Source Inverter with stabilized dc link). So, a dc distribution network is an effective way to interconnect distributed energy sources, without the problems of safety and reliability associated with the conventional distribution networks in ac.

Furthermore, electronic loads have recently become very common for several applications (adjustable speed drives, telecommunication and automation systems, etc.) and they impose voltage quality and service continuity requirements on distribution networks. A battery equipped dc network is able to fulfill these requirements, as well as a more traditional ac distribution network, with connected Uninterruptible Power Supply (UPS), but at a fraction of the cost.

There are several examples of small scale applicationspecific dc networks, such as: 1) safety power supply in Power Plants and Electrical Substations which are connected directly to the backup batteries; 2) on board ship supply networks [2], generally limited to high performance or military ships; 3) aerospace vehicles supply systems [3]; 4) emergency lighting systems.

Ship supply networks are the only example of a dc distribution network of considerable size and rated power with several different types of connected loads and generators.

\section{THE DC SUPPLY NETWORK}

Here attention is on a Low Voltage (LV) dc network for interconnection of light industrial loads; a dc distribution network is a new network, for which there is a substantial lack of standards and guidelines concerning Power Quality (PQ) issues and acceptable levels of conducted disturbances, as underlined in [4]. The significant conducted disturbance and the definition of suitable quality indices for harmonic/inter-harmonic and ripple phenomena have been described in [4], with reference to a series of product and environmental standards, which make reference to ac networks at various voltage levels and ac loads.

\section{RIPPLE DEFINITION AND RELATED INDICES}

\section{A. Ripple definition}

Ripple is defined as in [4] for a dc distribution networks with voltage level below $1000 \mathrm{~V}$. Ripple is the variation of quantity (voltage) about the steady state value during steady state electric system operation [8]. EN 61000-4-17 [6] states that the main sources of ripple disturbance are rectifier systems used in dc distribution networks and battery chargers. The standard indicates that the frequency of the ripple is the power frequency or its multiple 2, 3 or 6 , assuming a natural commutation rectifier as reference converter, with frequency and amplitude depending on rectifier architecture and degree of symmetry of the feeding transformer. However, several other rectifier converters have different operating principles and components with different conducted emissions patterns (also confirmed by Annex A in [6]): four quadrants converters (4QC) are built on a Voltage Source Inverter (VSI) architecture with a complex dc output voltage spectrum, depending on the characteristics of the supply ac network and its harmonic content [9]; ac/dc converters are often equipped with power factor correction units on the dc side, operating at few $\mathrm{kHz}$ switching frequency; dc/dc converter may be half and full bridge transformer coupled converters or simpler buck/boost converters, depending on requirements of power and voltage ranges, dynamic performance and regulation accuracy.

For all these reasons, ripple is a very complex subject. Ripple is interpreted often as a periodic variation around the steady state dc value, but not necessarily so [10]: this is the commonly referred peak-to-peak value and it is a scalar quantity, evaluated on a suitable interval $T$ (often related to 
an underlying fundamental network component, such as mains frequency in ac/dc converters) [10].

From a general point of view, without any information on the frequency of occurrence of a given transient disturbance, it is clear that even one single spike can determine a large ripple value despite its time duration. Here, evaluation of voltage ripple is proposed on three different frequency ranges: $2 \mathrm{kHz}$ ( $T=500 \mu \mathrm{s})$ for low frequency phenomena; 20 $\mathrm{kHz}(T=50 \mu \mathrm{s})$ to account for conducted disturbances from large power converters; $150 \mathrm{kHz}(T=6.7 \mu \mathrm{s})$ to account for conducted disturbances from small power converters (to be covered in accordance with the immunity counterpart standard EN 61000-4-16 [5]). This definition lends itself to a parallel interpretation and two implementations will be considered: a frequency domain analog filter bank and a wavelet bank.

\section{B. Ripple Power Quality index}

With reference to previous section, proper ripple $P Q$ indices and their expressions are defined. PQ indices may be defined in general [11] as "the concise numerical representations characterizing the nature of a PQ event based on the time and/or frequency information of the disturbance waveform. The effectiveness of PQ indices under practical circumstances is determined by the applicability of both their definitions and the measurement techniques", which will be emphasized in this Section. Pitfalls of several commonly used PQ indices under practical circumstances and for real cases are discussed in [12].

The electrical quantity $q(t)$ (voltage or current) is assumed to be sampled at a conveniently large sampling frequency $f s$ and a discrete time sequence $q[n]$ is obtained. The discrete frequency spectrum $Q[k]$ may be obtained with DFT on a suitable time-window.

The peak-to-peak value $q_{\mathrm{pp}}$ over $k_{T}$ samples interval (defined as $k_{T}=\operatorname{round}(T / d t)$ ) is:

$$
q_{p p, T}=\max _{n, k}\left\{q[n]-q\left[n+k+k_{T}\right]\right\}
$$

where $\max \{\}$ operation is done over admissible values of $n$ and $k$, positive integers, so that the two terms between curly braces cannot be "closer" than $k_{T}$ samples.

Two approaches are investigated here: a filter based approach, where the filter may be either digital or analog, and a DFT based approach, where the ripple results from the summation of the most significant frequency components.

1) Filter approach. The specification of the time window length $T$ for ripple evaluation down to $6.7 \mu$ s imposes a strict requirement on the minimum sampling frequency (about 1 MS/s per channel). So, at least for the two smallest $T$ values (50 $\mu$ s and $6.7 \mu \mathrm{s})$, alternative solutions have been investigated: an analog band-pass filter may be applied directly to the input signal.

$$
\tilde{q}_{p p, T}=\max _{t}\left\{\int q(u) h(t-u) d u\right\}
$$

The max value of the ac filtered signal is a direct estimation of the $q_{p p, T}$ quantity specified in (1). Roll-off and frequency selectivity of the band-pass filter are of concern.

In case of analog implementation there are some filter architectures with some benefits and drawbacks: Chebyshev filter has the steepest and sharpest roll-off at the corner frequency at the expense of frequency response oscillations (the so called "filter ripple"); Butterworth filter has no oscillations, but a smoother response profile around the corner frequency; both these filters have no linear phase response and only Bessel (with a conveniently increased order for similar sharpness around the frequency corner) keeps the phase response linear.

If a digital implementation is preferred, a FIR architecture (with up-sampler/down-sampler blocks) is convenient. This architecture has many advantages: linear phase response (results are different for "sum of amplitude" (SA) and "sum of amplitude and phase” (SAP) criteria shown below), stability, low computational complexity and control of initial transient response (limited duration), at the expense of a slightly larger minimum filter order for the same frequency response selectivity (in terms of sharpness at corner frequencies) with respect to other filter architectures.

2) DFT approach. In this case the spectrum $Q[k]$ is normally computed on a $T=1 \mathrm{~s}$ time window (other smaller $T$ values are probed anyway). The ripple index is the direct summation of the components above a given threshold thr, defined by the set of $k$ values $K_{\text {thr }}$, with SA and SAP expressions:

$$
\begin{aligned}
& q_{D F T, T, S A}=\sum_{k \in K_{t h r}}|Q[k]| \\
& q_{D F T, T, S A P}=\sum_{k \in K_{t h r}} Q[k]
\end{aligned}
$$

The thr value must be carefully chosen non to leave out any significant component and to keep the size of $K_{\text {thr }}$ as low as possible: a general rule is derived with the help of some real signals. Furthermore, in order to avoid the proliferation of spectral lines due to improved frequency resolution with longer time windows, a PeakDet() function was implemented, to isolate the largest peak of each spectral group. Some additional activity is needed to set optimal values for other parameters.

\section{RESULTS}

A set or real reference signals is used to evaluate the proposed expressions: the signals were recorded during conducted emissions tests of dc/ac converters connected to a weak power supply. The signal used in the foregoing analysis is \#000 over the [10-2000] $\mathrm{Hz}$ frequency range (the low frequency corner is limited by the characteristics of the probe used during the measurements); the ripple index $q_{p p}$ computed by (1) is 0.0316 at time instant $t^{*}=1.304$. 


\section{A. Filter approach results}

to be completed

\section{B. DFT approach results}

Results are estimated as a function of a series of parameters: the thr value; the overlap value $p$; time window length $T$ (other than the prescribed $0.1 \mathrm{~s}$ value).

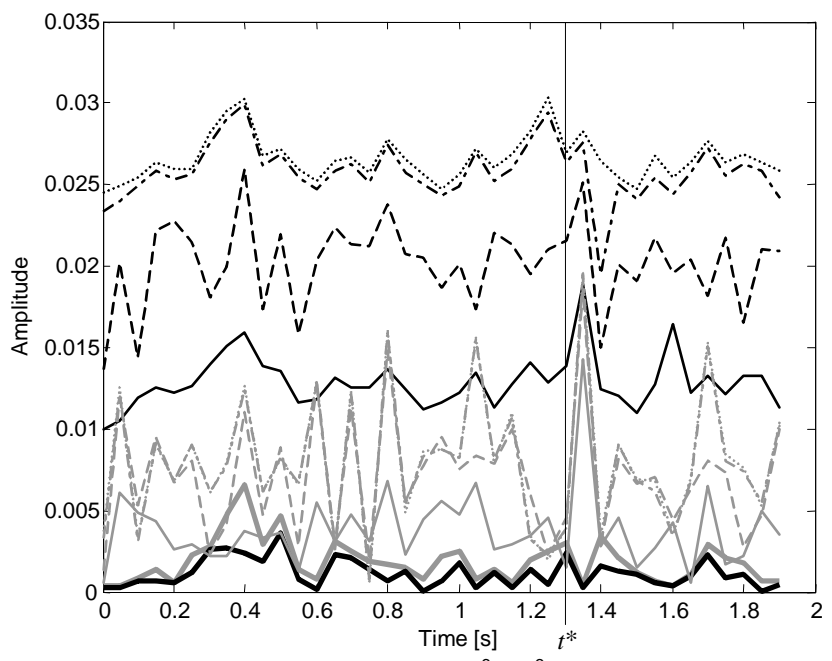

Fig. 1. DFT estimated ripple: thr $=\left[10^{-6}, 10^{-3}\right]$, SA black, SAP gray (thr $\left.=10^{-3}-, 10^{-4}-, 310^{-5}--, 10^{-5}-\cdot-\cdot-, 10^{-6} \cdots \cdots\right)$

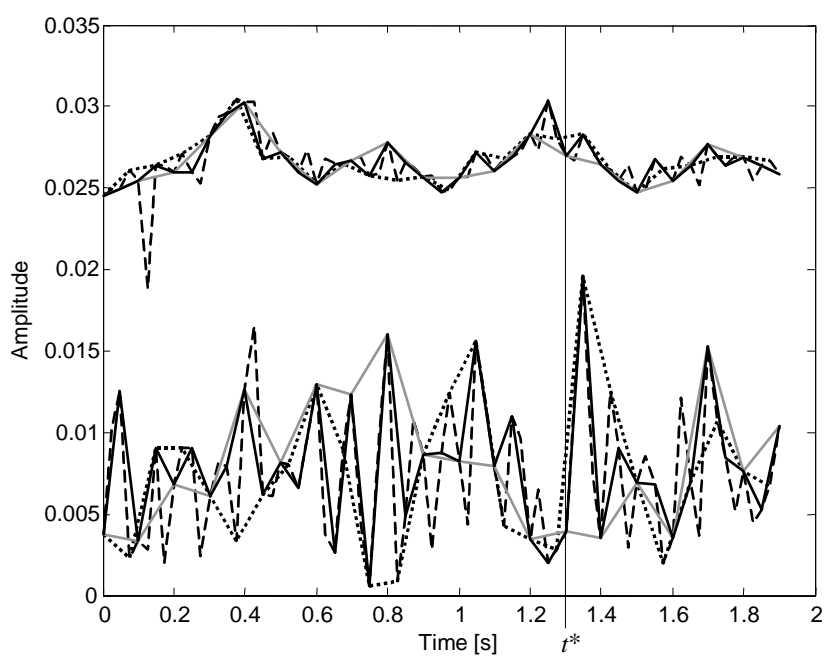

Fig. 2. DFT estimated ripple: overlap $=[0.25,1]$, SA above, SAP below

$$
(p=0.5-, p=0.25--, p=0.75 \cdots \cdots, p=1.0 \longrightarrow)
$$

With reference to Fig. 1 the best estimate of the ripple index is given by the SA curves for the lowest thr values in terms of $q_{p p}$ value and by the SAP curves for the instant of occurrence $t^{*}$. A "saturation" phenomenon occurs, since below a given thr value no other components are included in the determination of the ripple index $q_{D F T, T}$ (the two curves for thr $=10^{-5}$ and $10^{-6}$ are almost identical).

In Fig. 2 we observe small variations of the $q_{D F T, T, S A}$ for the considered overlap coefficients, with a more regular profile for $p=1.0$ (no overlap).

\section{CONCLUSIONS}

This work is a first attempt to define adequate Power Quality indices and related implementation for dc low voltage distribution networks and connected loads. Distributed generation and safety power supplies are the most recent and important applications, so that the subject is getting more and more interest.

The proposed expressions are tested with reference signals recorded during conducted emissions tests of dc/ac converters and they have proved to be consistent and to bear a true picture of the involved electrical phenomena.

The theoretical framework for prediction of algorithms behavior is under development and several tests are carried on to get a complete picture of the influence of algorithms parameters on the final result: good estimation of the ripple index and of the time instant of occurrence.

\section{REFERENCES}

[1] N. Hadjsaid, J.F. Canard and F. Dumas, "Dispersed Generation Impact on Distribution Networks", IEEE Computer Applications in Power, vol. 12, n. 2, pp. 22-28, Apr. 1999.

[2] M. Baran and N.R. Mahajan, "DC Distribution for Industrial Systems: Opportunities and Challenges", IEEE Transactions on Industry Applications, vol. 39, n. 6, pp. 1596-1601, Nov./Dec. 2003.

[3] E.W. Gholdston, K. Karimi, F.C. Lee, J. Rajagopalan, Y. Panov and B. Manners, "Stability of Large DC Power Systems using Switching Converters, with Application to the International Space Station", Intersociety Energy Conversion Engineering Conference, IECEC '96 Proc., Washington, DC, USA, Aug. 11-16, 1996, vol.1, pp. 166-171.

[4] M. Caserza Magro, A. Mariscotti, P. Pinceti, "Definition of Power Quality Indices for DC Low Voltage Distribution Networks", IMTC 2006, Sorrento, Italy, April 20-23, 2006.

[5] EN 61000-4-16, Electromagnetic compatibility (EMC) - Part 4-16: Testing and measurement techniques - Test for immunity to conducted, common mode disturbances in the frequency range $0 \mathrm{~Hz}$ to $150 \mathrm{kHz}$, 1998-02.

[6] EN 61000-4-17, Electromagnetic compatibility (EMC) - Part 4-17: Testing and measurement techniques - Ripple on d.c. input power port immunity test, 1999-08.

[7] EN 61000-4-29, Electromagnetic compatibility (EMC) - Part 4-17: Testing and measurement techniques - Voltage dips, short interruptions and voltage variations on d.c. input power ports, immunity tests, 200011.

[8] EN 61000-4-7, Electromagnetic compatibility (EMC) - Part 4-7: Testing and measurement techniques - General guide on harmonics and interharmonics measurements and instrumentation, for power supply systems and equipment connected thereto, 2002-08.

[9] A. Mariscotti, "Analysis of the dc link current spectrum in voltage source inverters", IEEE Trans. on Circuits and Systems - Part I, vol. 49, n. 4, Apr. 2002, pp. 484-491.

[10]MIL STD 704E, “Aircraft electric power characteristics”, May 1991.

[11]T. Lin and A. Domijan, "On Power Quality Indices and Real-Time Measurement”, IEEE Trans. on Power Delivery, vol. 20, n. 4, Oct. 2005, pp. 2552-2562.

[12] G.T. Heydt and W.T. Jewell, "Pitfalls of electric power quality indices," IEEE Trans. on Power Delivery, vol. 13, no. 2, Apr. 1998, pp. 570-578.

[13]I.W. Selesnick, M. Lang, and C.S. Burrus, "Constrained Least Square Design of FIR Filters without Specified Transition Bands", IEEE Trans. on Signal Processing, vol. 44 n. 8, Aug. 1996, pp. 1879-1892. 